\title{
Parental participation in influencing the unhealthy behaviour of adolescents in their excessive consumption of free sugars: a qualitative study
}

SADJ May 2019, Vol. 74 No. 4 p165 - p170

TE Okagbare ${ }^{1}$, S Naidoo ${ }^{2}$

\section{SUMMARY}

\section{Introduction}

The amount, and more importantly, the frequency, of free sugars consumed are strongly associated with the rate of caries formation and of periodontal diseases.

\section{Aims and objectives}

The aims and objectives of this qualitative study were to investigate the perceptions of parents regarding their influence of the unhealthy behaviour of South African adolescents in their excessive consumption of free sugars.

\section{Design}

The study design was qualitative exploratory and the research strategy, inductive, deductive and abductive.

\section{Methods}

Data were collected from five focus group interviews using the non-probability purposive theoretical sampling method and the data were analysed using the grounded theory approach.

\section{Results}

The parents contended that while natural sugars are acceptable, refined (free) sugars cause dental caries and gum diseases.

\section{Conclusion}

Parents attributed the excessive consumption of free sugars among adolescents to their availability both at home and in the stores as well as their affordability.

\section{Author affiliations:}

1. Tuweyire E Okagbare: BDS, PG Dip. (Odont), MSc (Odont), PhD., Department of Dental Public Health, Faculty of Dentistry, University of the Western Cape, South Africa.

ORCID Number: 0000-0002-8263-2866

2. Sudeshni Naidoo: BDS (Lon), LDS.RCS (Eng), MDPH (Lon), DDPH RCS(Eng), MChD (UWC), PhD(SU), Dip Int Research Ethics (UCT), DSc (UWC). Emeritus Professor, Faculty of Dentistry, University of the Western Cape, South Africa.

ORCID number: 0000-0001-7424-8082

Corresponding author: Tuweyire E Okagbare

Faculty of Dentistry, University of the Western Cape, South Africa,

Private Bag X1, Bellville 7535, South Africa.

Email: teokagbare@gmail.com

Author contributions:

1. Tuweyire E Okagbare: Principal Researcher - $60 \%$

2. Sudeshni Naidoo: Co-Author \& Advisor - $40 \%$
The present study recommends that babies be weaned off exclusive breastfeeding after six months with meals not sweeter than maternal breast milk and parents and schools should provide enabling environments that do not encourage excessive consumption of free sugars.

\section{Keywords}

Qualitative research, adolescents, taste buds, excessive free sugars, interventions, oral health, South Africa.

\section{INTRODUCTION}

The World Health Organization's (WHO) oral health promotion framework highlighted the need to integrate oral health into general health promotion. ${ }^{1}$ This was later reiterated by Watt and Sheiham, emphasising the New Public Health approach to public health promotion using the common risk factor model to improve dental and oral health, rather than the biomedical approach to health. ${ }^{2}$ This is because caries and periodontal disease are chronic diseases that share risk factors with other major chronic systemic conditions. ${ }^{3}$

Although the efficacy of fluorides and fissure sealants as caries preventive measures have been shown in systematic reviews, ${ }^{4}$ they do not sufficiently combat its progression. $^{3}$

There was therefore a need to expand interventions to target the major risk factor of the disease, free or fermentable sugars which are also implicated in other systemic conditions such as diabetes and obesity, in order to prevent the occurrence of caries in the first instance. ${ }^{3}$ This premise informed the recently updated $\mathrm{WHO}$ guidelines on sugar consumption. ${ }^{5}$

The amount and more importantly the frequency of consumption of free sugars found in table sugar, confectionery, soft drinks, biscuits, honey, cakes, sweets, chocolate and fruit juice are strongly associated with the rate of caries formation and periodontal diseases. ${ }^{6,7}$ Free sugars are not as healthy as the naturally occurring intrinsic sugars which include breast milk sugars ${ }^{8}$ and those naturally present in honey, syrups and unsweetened fruit juices. Free sugars are comprised of monosaccharides and disaccharides which are added to foods by the manufacturer, cook or consumer. 
In general, the cheapest foods are high in fat and sugar. ${ }^{9}$ This is partly responsible for the high consumption rate of soft drinks and sweets among adolescents in preference to the more nutritionally advantageous meals of fruits and vegetables. ${ }^{10}$ The implications for caries formation and periodontal disease are well documented. ${ }^{6,11}$

Poor oral hygiene and inadequate/infrequent tooth brushing together with the inappropriate consumption of free or fermentable sugars (both visible or table sugar and hidden sugars consumed in processed or manufactured foods and drinks) lead inexorably to the accumulation of thick destructive bacterial plaque that produces lactic acid. ${ }^{6}$ It has been suggested that the brushing of teeth immediately after eating sugary foods may not adequately prevent the harmful effects, but rather it may be better to brush before a sugary meal or snack as this helps to remove plaque, reducing the bacterial population and hence the quantity of acid produced. This is because plaque bacteria will start producing acid as soon as fermentable sugar enters the mouth. ${ }^{6}$

In addition to sugars being cheaper when compared with more nutritional products, their easy availability at homes, in schools and in the shops also contributes to their high consumption among adolescents. ${ }^{9}$

A Minnesota study reported that the association between the availability and consumption in schools was stronger for chocolates and other candies among seventh graders but was not significantly associated with older learners (grades 9-10). ${ }^{12}$ In South Africa, it was found that just over half of adolescent learners drink sugar-sweetened beverages and $42.6 \%$ eat cakes and/or biscuits often, with no significant variation in gender. ${ }^{13}$ Inappropriate consumption of free sugars is therefore a major public health concern in South Africa with implications for reduced oral/general health-related quality of life and escalated costs of health care.

Our understanding of the perception of parents of the psychosocial factors associated with excessive and inappropriate consumption of free sugars among adolescents in South Africa is very important because they are key role players and role models who influence the behaviours of their children. The present study explored these perceptions of parents and the challenges they face trying to overcome the problem.

\section{METHODS}

Approval for this study was obtained from the Senate Research Ethics Committee of the University of the Western Cape, South Africa (Ref No. 11/1/55).

The details of the sampling procedure have previously been published. ${ }^{14}$ Briefly, five focus groups (minimum of six participants each) interviews took place between the months of March and November, 2015.

The qualitative nature of the study required that saturation governed the sample size. ${ }^{15}$ Theoretical saturation was achieved at the fourth focus group interview which was in line with Krueger and Casey's assertion that most focus group interviews saturate at the third or fourth instance. ${ }^{16}$ The sample size of the first four focus group interviews was 31.
The fifth focus group interviews were conducted not only to enhance saturation but also to bring the sample size to over 31, in line with other studies worldwide that used qualitative approaches and qualitative interviews as the method of data collection. ${ }^{17}$ According to Gill et al. the optimum size for a focus group is six to eight participants (excluding researchers). ${ }^{18}$ Participation was based on the criterion of being a past/current parent or caregiver to an adolescent.

Confidentiality was maintained throughout the study by the use of pseudonyms to ensure that the identities of the participants were not revealed. The researcher explained to participants the purpose of the study, ensuring their understanding, and presented the ethical approval for the study. Further, the parents read and signed the informed consent forms. At the beginning of every interview the researcher obtained permission from the participants to use the audio recorder. They were also informed that their participation in the interview was completely voluntary, confirming that any may refuse to answer any questions and that anyone was free to withdraw from the interview at any time without consequences.

\section{Profile of participants}

A total of 37 participants who were homogeneous in the sense of shared experience of living in the same neighbourhood (but diverse in terms of professions) were recruited. Their mean age was 46.3 years [95\% $\mathrm{Cl}=43.0$-49.5]. Although no attempt was made to achieve a provincially representative sample, the study endeavoured to ensure that the data was not skewed by accommodating participation from both the urban areas (Alberton in East Rand/Ekurhuleni Municipality, Hillbrow in Johannesburg Municipality and Gezina in Tshwane Municipality) and semi-rural areas (Katlehong in East Rand/Ekurhuleni Municipality and Soweto in Johannesburg Municipality). Representation from amongst the four racial groupings in South Africa (Black, Coloured, Asian/Indian and White) was achieved and the views of the two largest global religious movements (Christianity and Islam) were obtained.

\section{Study design and sampling procedure}

The study was a Double-Layer Design, with geographic areas as the first layer and the different audiences as the second layer and was also qualitative exploratory. The research strategy used was inductive, deductive and abductive. A non-probability purposive theoretical sampling method was used.

\section{Data collection}

The interviews of the five focus group participants took place in venues acceptable and accessible to all the interviewees. To ensure that the participants met the inclusion criterion the researchers used as the opening question: "Please tell me, have any adolescents between the ages of 10 to 19 years lived with you or are living with you at the moment?". Each qualifying participant was requested, after consent had been obtained, to complete a short questionnaire on their demographic characteristics. A semi-structured interview guide was used, which had been developed to ensure consistency in data collection from the focus group interviews, yet allowing the 
sessions to be sufficiently flexible to encourage the natural flow of conversation in the groups. The interview guide included a series of open-ended questions in order to reduce the chances of priming the discussion, allowing the participants to freely express themselves. The questions were designed to stimulate discussion among parents regarding factors they perceived to be associated with the health-compromising behaviour of inappropriate consumption of refined sugars among adolescents in South Africa. Professionals were implored to use layperson's language for the benefit of others and also to reduce any likelihood of inhibition. To ensure that all participants had equal opportunity to contribute, the respondents took turns to enter the debate. The average time span of the five focus group interviews in this study was $1 \mathrm{hr} 45 \mathrm{mins}$.

\section{Data analysis}

The data analysis used in this study followed the grounded theory approach. Data analysis of the transcripts began with Open (Substantive) and Axial Simultaneous Coding method (First and Second Cycle coding processes) which was employed right from Initial Coding to integrated data analysis. In order to reduce bias, an independent coder, a specialist in Community Dentistry was also engaged.

\section{RESULTS}

The sample size of 37 determined by theoretical saturation, included a mixed group: 23 fathers, one grandfather; 10 mothers and three grandmothers. Thirteen had received a tertiary education while 14 had matriculated. Ten had not reached matric level. Altogether, the recruitment yielded 25 Blacks, seven Coloured, three Indians and two Whites. Thirty were church attendees and seven were Muslims.

The results of the data analysis were articulated in the following excerpts from the transcripts of the interviews and are presented in two sections:

1. Adolescent unhealthy behaviour of inappropriate consumption of sugars.

2. Parental participation.

Adolescent unhealthy behaviour of inappropriate consumption of sugars

\section{Adolescent upbringing}

Study participants were unanimous regarding the importance of the home environment and the role of a good upbringing in the formation and retention of healthy behaviours.

There was a total agreement among the participants that unhealthy behaviours of parents have a significant effect on the tendency of their adolescent offspring towards unhealthy behaviours.

Parents are powerful role models and their children emulate their characters and characteristics as they in turn grow up to be adults and therefore, the behaviour of parents should be positively exemplary. Children learn by what they see, more than what they hear and are told. A few participants disclosed that they did indeed practice some unhealthy behaviours such as excessive sugar consumption. Some parents are aloof, one parent even asserted that his adolescent children will outgrow their currently excessive consump-tion of sugars but another countered that assertion. Below are excerpts from the contributions of some participants:

"I also wanted to add about parents being a good role model to their child... you have to practice what you preach."

"They will outgrow eating sugar and chocolate..."

"Some of the things adolescents do... depends on the behaviour of the parents at home."

"I've got a problem with sugar and was in hospital 2010 because I was consuming too much Coca-Cola. I was drinking three to four litres of Coca-Cola a day... this is not a good example..."

"I'm concerned with excessive intake of sugar because I know that my kids like sweets and chocolates..."

\section{Adolescent preferences and taste buds}

The study participants expressed their concern regarding adolescents' preference and craving for refined sugars, as illustrated by the excerpts below.

"So you see it is now also about our taste buds not about the, the natural goodness..."

"...put a cucumber and a lunch bar and ask the child to pick. It is a simple thing - the lunch bar, obvious choice.

"You cannot drink the tea my daughter drinks. There is too much sugar."

"The sugar content is all about craving... for sweets, chocolate, and if you have self-esteem, you have confidence,... discipline... to abstain from it."

Influence of school environment, friends and peers All the participants highlighted the significant influence of friends, peers and school environment on the acceptance and practice by adolescents of the unhealthy lifestyle of inappropriate consumption of sugars. Some of their responses were:

"Even then if you can say to the child don't eat sweets there will be a friend there at the street to give him sweets".

"Even in most nursery schools they have packets of sweets they give to the children and I think that it definitely affects their emotions so children become very hyperactive and that can affect their concentration".

\section{Influence of advertisements, marketing, negative} mass and social media

Advertising and marketing on television of unhealthy behaviours and products attract adolescents. The negative influences of mass and social media especially via the Internet was also reported by study participants as a significant factor driving adolescents to excessive consumption of sugars. Some excerpts from the participants:

"And marketing. Coke looks good until..."

"The only things that are being advertised are the sweets, the good things that taste nice..."

"Like on TV, in the movies... mostly what you see is what is what you do..." 


\section{Availability, affordability of sugars}

Many of the participants lamented that some parents spoil their adolescents with too much spending money and that ready availability of unhealthy products at home and in the shops and their affordability attract adolescents to indulge, as shown by the excerpts below:

"It's because there are sugars and sweets everywhere, at home, the tuck shops are everywhere, always selling sweets..."

"Parents, they really spoil their children by giving kids spending money to get what they want..."

\section{Parental participation}

This section is conceptualised as a multifaceted construct grounded in the interview data, having the following components: Parental knowledge and the Challenges faced by parents of adolescents.

\section{Parental knowledge}

The participants in the present study indicated that parents need to be knowledgeable regarding the effects of unhealthy consumption of sugars on the teeth and gums if they are to be able to provide reasons to support what they say to their adolescent children. While most appeared to be knowledgeable, some also disclosed consuming large amounts of sugar and sugary drinks themselves. The Muslim participants claimed that they depend solely on their religion as their guide. Some of the responses of the participants:

"What I think, is that there are natural sugars and there are sugars coming from companies. So for the natural sugar you can eat as much as you want, but processed sugar from the companies have chemicals in them which are not good for your body."

"Too much sugar is very bad for the teeth and health and your chances of getting tooth decay are worse than one who takes little or no sugar."

"Everything, in our religion teaches us balance... excess sugars leads to negative effects. But even sugars, you need a bit of sugar in your diet but everything needs a balance. Vegetable, fruit, natural, anything natural is encouraged."

\section{Challenges faced by parents of adolescents}

The participants declared the challenges they face included the influence of the school environments, peer pressure, mass and social media. Parents are unable to protect their children from bad influences once outside the home, asserted an elderly parent.

"At the end of the day the child learns all these things through TV, you know, from the media, at school, peer pressure, all of them".

\section{DISCUSSION}

Inappropriate consumption of free sugars by adolescents was found to be a major concern of parents in this study. This concern is substantiated by the findings of Reddy et al., who found that in South Africa $50.3 \%$ of adolescent learners drink sweet cool drinks and $42.6 \%$ often eat cakes and/or biscuits. ${ }^{13}$ Similarly, Currie et al., reported that among European school-aged children there was an increased consumption of soft drinks and sweets in preference to the more nutritional advantageous meals of fruits and vegetables ${ }^{10}$ with potentially serious implications for caries formation.

The importance of the home environment and the role of a good upbringing in the formation and retention of healthy behaviours was acknowledged during the interviews. There was also a total agreement that unhealthy behaviours of parents have significant effects on their adolescents' tendency towards similar unhealthy behaviours.

Therefore, parents behaviours should be positively exemplary - "they should practice what they preach". However, children learn more by what they see than what they hear and are told. This notion concurs with the suggestion of a study that examined who 679 African American ninth-graders who were themselves admired and looked up to in their own environments; that role model effects are separate from parenting effects and indeed are more critical. ${ }^{19}$ On the contrary, few of the parents disclosed that they indulged in the unhealthy behaviour of excessive sugar consumption.

One parent even asserted that he believed his adolescent children will outgrow the excessive consumption of sugars... but he was promptly reminded by another parent of his own inability to outgrow his love for Coke.

Even though some of these parents admitted their own susceptibility, they also confessed that they were not setting a good example. These views were in agreement with the argument of Gibson et al. ${ }^{20}$ that parental' positive influences are vital for establishing healthy lifestyle behaviours in their adolescent children.

Concerns regarding the spoiling of adolescents by parents giving them too much spending money may be increased by the report that some parents hand their children sweets to pacify them, thereby encouraging the inappropriate consumption of sugars. According to Schwartz et al., the practice is due to their lack of practical strategies on how to properly train their children. ${ }^{21}$

A positive consideration is that adolescents with high self-esteem are likely to be more concerned with their health and wellbeing, effectively associated with eating healthily. ${ }^{22}$ Parents should therefore, appreciate and cherish their adolescents in order to help to build and enhance their self-esteem.

This study confirmed the significant influence of the friends, peers and school environment on the lifestyle attitudes of children. Nursery schools who give sweets to the children to pacify them, and the sharing of chocolates and sweets among adolescents at schools and neighbourhoods, override the efforts of those parents who try to keep their offspring on natural diets including fruit and vegetables. Children from immigrant Mexican households in the United States have been seen to abandon traditional foods prepared at home in favour of the higher-calorie foods, beverages, and snacks they consume at school. ${ }^{23}$ 
Globalization has also been found to be contributory in increasing the availability of fast foods and sweets in schools. ${ }^{24}$ School snack lines, vending machines, and in-school stores typically offer less-than-optimal food choices, including sweetened soft drinks, fried chips, candies and other confectionaries. ${ }^{25}$ This is also the inference of the report of a workshop organised by the Institute of Medicine (US) and National Research Council (US) Committee on the Science of Adolescence that analysed many studies investigating the influence of environment on adolescents. ${ }^{26}$

Adolescents are exposed to many advertisements for sweetened drinks, fast food restaurants and highcaloric snacks on television commercials, such as CocaCola drinks, Red Bull energy drink and Doritos snacks, some of the favourites among South African youth. ${ }^{27,28}$ The influences of mass and social media especially via the internet are significant factors driving the consumption of free sugars.

The present study acknowledged that parents need to be aware of the effects of the unhealthy consumption of free sugars on the teeth and gums and should be able to provide reasons to support whatever information they give to their children. Paradoxically, some disclosed consuming large amounts of sugar and sugary drinks themselves, despite their understanding of the dangers. However, they all agreed that while natural sugars were acceptable, free sugars cause caries and gum diseases. This consensus is in line with the findings of Frances et al., who reported that the amount, and more importantly the frequency, of consumption of free sugars found in table sugar, confectionery, soft drinks, biscuits, cakes, sweets, chocolate, honey and fruit juice is strongly associated with caries formation and periodontal diseases. ${ }^{7,11}$

This inappropriate consumption of free sugars is likely to lead to high prevalences of caries and of obesity among adolescents. ${ }^{29}$ It is recognized, however, that there is little strong evidence to support this contention in South Africa but that may be due to the lack of updated epidemiological data at the national level for the adolescent subgroup, even from the National Children's Oral Health Survey conducted by the Department of Health,.

Substituting fruit juice for solid or whole fruits is not recommended because the fruits themselves not only contain less sugars (approximately 35\% less), but their intracellular sugars are healthier than the extracellular sugars produced when cell membranes rupture during the juicing process. Solid or whole fruits also provide lot more nutrition and fibres that are usually lost in the juicing process. ${ }^{30}$

Infants have innate preferences towards certain taste qualities and dislikes of other tastes. ${ }^{31}$ Infants prefer sweet-tasting foods and reject foods that do not taste as good, such as certain vegetables. This reflects an evolutionary response that was historically useful because the sweet taste signaled sources of energy (e.g. the breastmilk, their first source of calories), while bitter tastes signaled foods that might be toxic. However, some researchers suggest that infants begin to accept bitter tastes around the age of $14-180$ days. ${ }^{32}$ As they grow up, they may refuse certain foods and become picky about their intake. This presents many challenges for parents, who respond in a variety of ways. Some give their children what they want to pacify them and end up encouraging inappropriate consumption of sugars.

As commonly reported in adolescent literature, ${ }^{33}$ the parents in the present study stated that the challenges they faced with regard to educating their children about their diet included the influence of school environment, peer pressure, and the negative influences of mass and social media. Once adolescents left home, parents were unable to protect them from the bad influences outside of the home environment. However, Muslims claimed that they depend solely on their religion as their guide and the consensus was it takes the whole community to provide the enabling environment needed to reduce the excessive consumption of free sugars among adolescents.

\section{Limitations}

The findings of this study should be interpreted in the context of the limitations imposed by the methodology. First, the limitations of qualitative research include the fact that the results are not generalisable to the larger population of parents because of the use of non-probability, purposive sampling strategy and the small number of research participants.

In addition, not all views may have been adequately represented due to selection bias. It also plausible that some parents may have provided socially desirable responses and the responses of some parents may have been influenced by the opinions and comments of more vocal parents.

\section{CONCLUSION}

It was hoped that the findings of this study would provide a scientific evidence-base to inform the planning of priority public health programmes to improve parental participation in the prevention and control of excessive consumption of free sugars among adolescents. In spite of the limitations described above, the findings of the study are relevant and profound.

This qualitative study highlighted the need for parents to be cognisant of the important role they play in the prevention, initiation and control of the unhealthy behaviour of excessive sugar consumption among adolescents. Efforts should be made by parents to properly nurture and train their children from infancy through preadolescence against inappropriate consumption of sugars.

Consequently, the present study recommends that, in addition to the updated $\mathrm{WHO}$ guidelines on sugar consumption, babies be weaned after six months exclusive breastfeeding with meals not sweeter than the maternal breast milk the baby is already used to and that further research be initiated into this option. Parents and schools should provide enabling environments that do not encourage excessive consumption of free sugars. 


\section{References}

1. Petersen PE. Global policy for improvement of oral health in the $21^{\text {st }}$ century - implications to oral health research of World Health Assembly 2007, World Health Organization. Community Dent Oral Epidemiol. 2009; 37: 1-8.

2. Watt RG, Sheiham A. Integrating the common risk factor approach into a social determinants framework. Community Dent Oral Epidemiol 2012; 40: 289-96.

3. Schulte AG, Tsakos G. The joint ORCA-EADPH symposium on sugar: the oral health perspective - a commentary. Caries Res. 2019; 53:145-8.

4. Tonetti MS, Bottenberg P, Conrads G. Dental caries and periodontal diseases in the ageing population: call to action to protect and enhance oral health and well-being as an essential component of healthy ageing - Consensus Report of Group 4 of the joint EFP/ORCA workshop on the boundaries between caries and periodontal diseases. J Clin Periodontol. 2017; 44:S135-S44.

5. World Health Organization: Guideline: Sugar Intake for Adults and Children. Geneva, World Health Organization, 2015.

6. Moynihan PJ, Kelly SA. Effect on caries of sugar restricting intake. Systematic review to inform WHO guidelines. J Dent Res. 2013; 93:98-118.

7. van Loveren C. Sugar restriction for caries prevention: amount and frequency. Which is more important? Caries Res. 2019; 53:168-74.

8. Bradbury J, Mulvaney CE, Adamson AJ, Seal CJ, Mathers JC, Moynihan PJ. Sources of total, non-milk extrinsic, and intrinsic and milk sugars in the diets of older adults living in sheltered accommodation. Br J Nutr. 2008; 99:649-52.

9. Watt RG, Rouxel PL. Dental caries, sugars and food policy. Arch Dis Child. 2012; (Online). Available from: doi: 10.1136/ archdischild-2012-301818 (Accessed 14/08/2018)

10. Currie C, Roberts C, Morgan A, et al. eds. Young People's Health in Context: Health Behaviour in School-Aged Children (HBSC) Study. International report from the 2001/2002 survey. Health Policy for Children and Adolescents no. 4. Copenhagen: WHO Regional Office for Europe, 2004.

11. Frances K, Hird V, Lobstein T, Stayte L, Vaughan A. Sweet and sour. The impact of sugar production and consumption on people and the environment. London: Sustain, 2000.

12. Kubik MY, Lytle IA, Hannan PJ, Perry CL, Story M. The association of the school food environment with dietary behaviours of young adolescents. Am J Public Health. 2003; 93: 1168-73.

13. Reddy SP, James S, Sewpaul R, et al. Umthente Uhlaba Usamila - The South African Youth Risk Behaviour Survey 2008. Cape Town: South African Medical Research Council, 2010.

14. Okagbare TE, Naidoo S. Parents' perception of psychosocial factors, health compromising behaviours and oral health among adolescents in South Africa. SADJ 2018; 73: 221-7.

15. Struebert-Speziale HJS, Carpenter DR. Qualitative Research in Nursing. $4^{\text {th }}$ ed. Philadelphia: Lippincott, 2007.

16. Krueger RA, Casey MA. Focus Groups: a Practical Guide for Applied Research. $3^{\text {rd }}$. London: Sage, 2000.

17. Mason M. Sample size and saturation in PhD Studies using qualitative interviews.

Forum: Qualitative Soc Res. 2010; 11: 1-19.

18. Gill P, Stewart K, Treasure E, Chadwick B. Methods of data collection in qualitative research: interviews and focus groups, Br Dent J. 2008; 204:291-6.

19. Bryant AL, Zimmerman MA. Role models and psychosocial outcomes among African American adolescents. J Adolesc Res. 2003; 18: $36-7$.

20. Gibson EL, Kreichauf S, Wildgruber A. A narrative review of psychological and educational strategies applied to young children's eating behaviours aimed at reducing obesity risk. Obes Rev. 2012; 13: 85-95.

21. Schwartz C, Scholtens P, Lalanne A, Weenen H, Nicklaus S. Development of healthy eating habits early in life: review of recent evidence and selected guidelines.

Appetite 2011; 57: 796-807.
22. Wiefferink $\mathrm{CH}$, Peters L, Hoekstra F, Dam GT, Buijs GJ, Paulussen TG. Clustering of health-related behaviours and their determinants: possible consequences for school health interventions. Prev Sci. 2006; 7: 127-49.

23. Caprio S, Daniels SR, Drewnowski. A et al. Influence of race, ethnicity, and culture on childhood obesity: implications for prevention and treatment. A consensus statement of Shaping America's Health and the Obesity Society. Diabetes Care 2008; 31: 2211-21.

24. Bruss MB, Morris JR, Dannison LL, Orbe MP, Quitugua JA, Palacios RT. Food, culture, and family: exploring the coordinated management of meaning regarding childhood obesity. Health Commun. 2005; 18: 155-75.

25. Duijster D, De Jong-Lenters M, Verrips E, Van Loveren C. Establishing oral health promoting behaviours in children parents' views on barriers, facilitators and professional support: a qualitative study. BMC Oral Health 2015; 15:157-70.

26. Institute of Medicine (US) and National Research Council (US) Committee on the Science of Adolescence. Influence of environment: many studies documented in The Science of Adolescent Risk-Taking: Workshop Report. Washington (DC): National Academies Press (US), 2011.

27. Dixon HG, Scully ML, Wakefield MA, White VM, Crawford DA. The effects of television advertisements for junk food versus nutritious food on children's food attitudes and preferences. Soc Sci Med. 2007; 65:1311-23.

28. South Africa youth's favourite brands. Sunday Times Generation Next survey, 2018.

29. Kantovitz KR, Pascon FM, Rontani RMP, Gavião MBD. Obesity and dental caries - a systematic review. Oral Health Prev Dent. 2006; 4:137-44.

30. Crowe KM, Murray E. Deconstructing a fruit serving: comparing the antioxidant density of select whole fruit and $100 \%$ fruit juices. J Acad Nutr Diet. 2013; 113:1354-8.

31. EUFIC Food Today. Tastes differ - how taste preferences develop 2011; (Online). Available from: http://www.eufic.org/ article/en/page/FTARCHIVE/artid/how-taste-preferencesdevelop/ (Accessed 25/03/2016).

32. Mennella JA, Beauchamp GK. The early development of human flavor preferences. In Capaldi ED, ed. Why We Eat What We Eat: the Psychology of Eating. Washington, DC: American Psychological Association, 1996.

33. A Parent's Guide to Surviving the Teen Years. https://kidshealth.org/en/parents/adolescence.html. (Accessed 03-04-2018) 